\title{
TNTERNAL FRICTION BEHAVIOUR OF SOME FERROMAGNETIC AMORPHOUS ALLOYS
}

\author{
M. ABOKI, G. BOISSEAU and G. BOUQUET \\ Laboratoire de Métallurgie structurale, Ecole Nationale \\ Superteure de Chimie, 11, rue Plerre et Marie Curie, \\ 75231 Paris cedex 05, et Centre d'Etudes de Chimie \\ Métallurgique (CNRS), F-94400 Vitry-sur-Seine, France
}

Résumé - La technique du frottement intèrieur à basse fréquence(1Hz)a été utilisée afin d'étudier les réarrangements atomiques susceptibles d'intervenir dans les verres métalliques ferromagnétiques sous l'effet de la tempërature entre l'ambiante et $550^{\circ} \mathrm{C}$

Pour les alliages étudiês, tels que FeBSi,FeBSiCrC et FeniMoB, le domaine de température envisagé a permis de suivre les évolutions structurales correspondant à la relaxation structurale et aux processus de cristallisation.

L'influence d'un écrouissage ou d'un pré-recuit a également été abordée.

Abstract - In order to study the atomic reorganization occurring in ferromagnetic metallic glasses under the effect of the temperature between 20 and $550^{\circ} \mathrm{C}$, internal friction experiments have been carried out on an inverted pendulum at low frequency (1 Hz).

For the studied alloys such as FeBSi,FeBSiCrC and FeNiMoB, the chosen temperature range permitted us to investigate the atomic configurations evolution corresponding to structural relaxation and crystallization processes.

Furthermore, we studied the influence of cold-working or pre-annealing treatments on the internal firiction spectra.

\section{INTRODUCTION}

We studied atomic rearrangements occurring in amorphous alloys as a function of the temperature in order to define the ideal temperature range in which diffusion experiments between metallic amorphous films could be tempted. In this aim various ferromagnetic amorphous alloys have been tested by internal friction measurements at low frequency $(1 \mathrm{~Hz})$ between room temperature and $550^{\circ} \mathrm{C}$. For this temperature range, structural relaxation and crystallization phenomena are abble to take place in the studied materials:FeBSi,FeBSiCrC,FeBSiC and FeNiMoB alloys.Only the results concerning FeBSi,FeBSiCrC and FeNiMoB will be presented here and in the following text these alloys will be named respectively " $A, B$ and $C$ ".

Furthermore our investigation consisted of the modification of the internal friction spectrum shape of the alloys, under the influence of various structural states.

\section{EXPERIMENTAL RESULTS}

Internal friction spectra of "as-cast" alloys. A typical internal friction spectrum of FeBSi amorphous alloy (A), is presented in Fig.la. In this figure we can note that after a non-significant initial evolution of $\mathrm{Q}^{-}-\left(20-200^{\circ} \mathrm{C}\right)$, the spectrum exhibits some anomalies consisting of a low and large maximum at about $300^{\circ} \mathrm{C}$, two litele maxima between 350 and $450^{\circ} \mathrm{C}$ and lastly high and sharp maxima at about $550-570^{\circ} \mathrm{C}$.

The internal friction spectrum presented in Fig.lb refers to FeBSiCrC alloy (B). The $Q^{-1}$ evolution is similar to that of $A$ alloy in that sense that comparable anomalies occur but not necessarily at the same temperatures. 


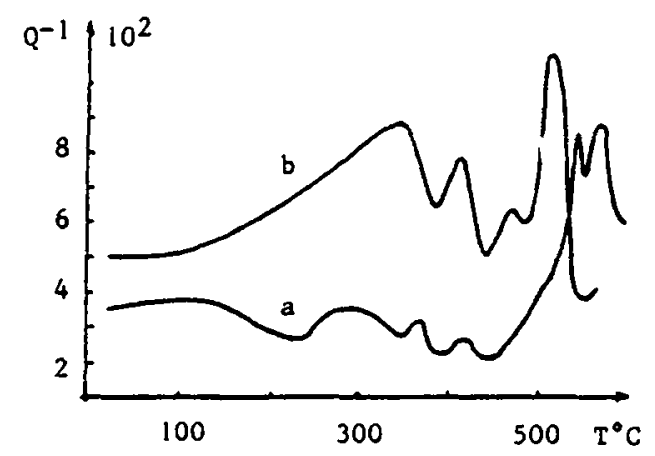

Fig. I

Internal friction spectra as a function of the remperature:

- la :"as-cast" FeSiB alloy

- 1b :"as-cast" FeSiBCrC alloy.

In Fig.2 we have reported the internal friction spectrum of FeNiMoB alloy (C). In regards to the previous spectra, we can note a really different behaviour of the material under the influence of temperature. Indeed, we note an initial decrease of $Q^{-1}$ background between room temperature and $150^{\circ} \mathrm{C}$. Above this temperature the internal friction increases, leading to two large maxima, respectively at about 250 and $350^{\circ} \mathrm{C}$, and lastly to a high and narrow maximum at $540^{\circ} \mathrm{C}$.

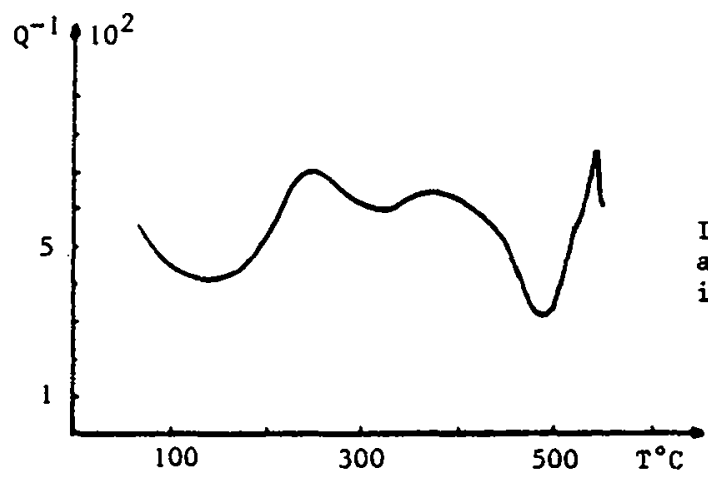

According to these results, the internal friction evolution appears appreciably different from one alloy to the other.Consequently the question is whether the chemical composition or the structural state is responsible of each kind of behaviour. In order to throw light on this last subject, experiments have been carried out with various initial structural states for the alloys.

Internal friction spectra of cold-worked specimens. FeBSi and FeBSiCrC alloys were initially cold-worked by scratching the two sides of the flat specimens with abrasive paper.The corresponding internal friction spectra are reported in Fig. 3.

In this figure we can note that the initial $Q^{-1}$ background is much higher than in the case of "as-cast" specimens and that only a little recovery of $Q^{-1}$ is performed under the influence of low temperatures $\left(20-150^{\circ} \mathrm{C}\right)$. The internal friction maximum which appeared at about $300^{\circ} \mathrm{C}$ in the case of "as-cast" A and B specimens, is always observed,but this maximum is higher and narrower in the present case. The enhancement of this maximum will be discussed later. Above $400^{\circ} \mathrm{C}$ and $350^{\circ} \mathrm{C}$ for $A$ and $B$ alloys respectively, the internal friction spectra exhibit the same behaviour that in the case of "as-cast" materials. 


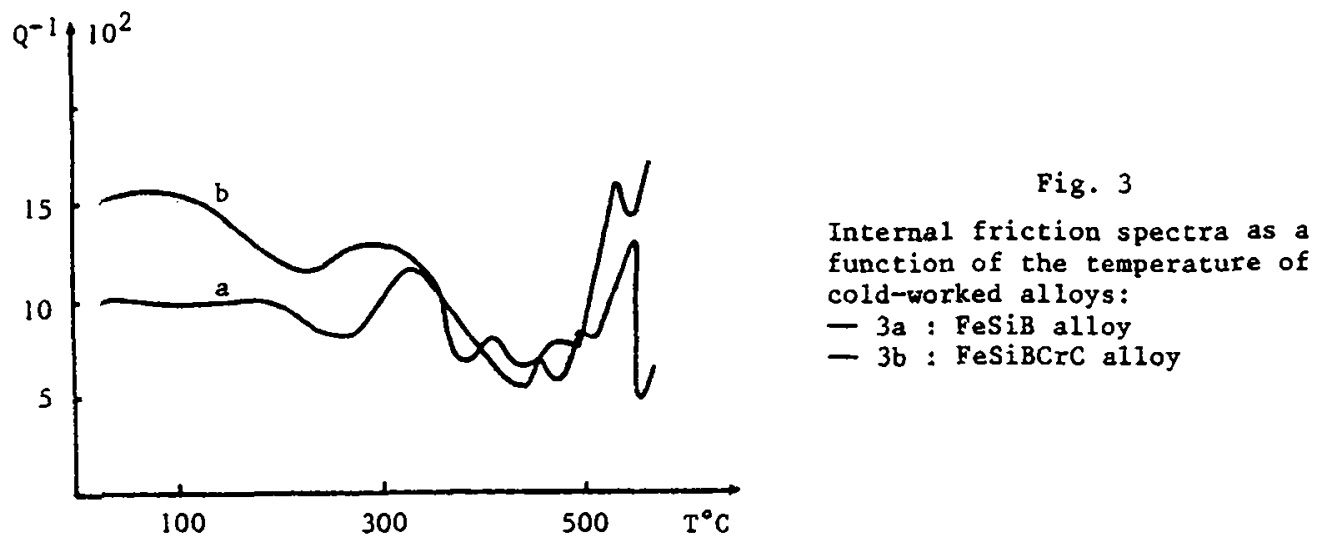

Internal friction spectra of pre-annealed specimens. According to the previous results and depending on the nature of the amorphous alloys rested, we could notice that the initial evolution of $Q^{-1}$ between 20 and $200-250^{\circ} \mathrm{C}$ could be either a decrease or an increase or even a plateau. In the case of a decrease as it is observed for $A$ and $C$ alloys, it is suggested that the "as-cast" structure can be stabilized by annealing treatments. I been described after pre-annealing treatments of the various alloys.The results are reported in Fig. 4 and Fig.5 for $A$ and $C$ alloys respectively.

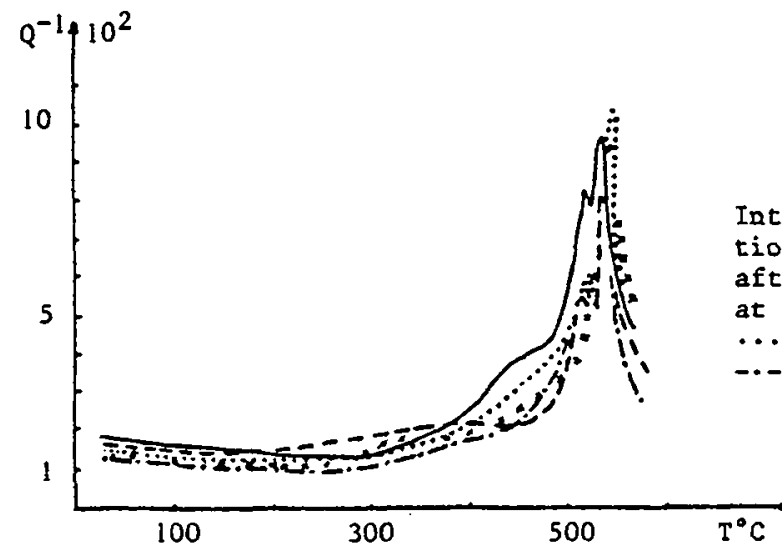

Fig. 4

Internal friction spectra as a function of the temperature of FeSiB alloy after various pre-annealing treatments at $350^{\circ} \mathrm{C}$ :

.. 2 hours, -- 3 hours, - 5 hours, -.- 7 hours.

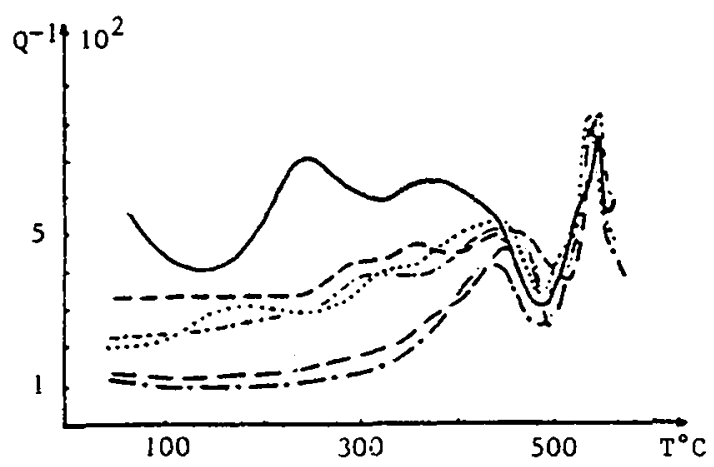

Fig. 5

Internal friction spectra as a function of the temperature of FeNiMoB alloy after various pre-annealing ireatments at $300^{\circ} \mathrm{C}:$ - "as-cast", . 10 min., -- 20 min., -.. I hour, - 5 hours, - -9 hours 
As in the case of "as-cast" conditions, the behaviour of these alloys is remarkably different. For $A$ alloy the internal friction decreases after short-time pre-annealings and reaches a value, stable up to $400^{\circ} \mathrm{C}$. Above this cemperature, internal friction increases sharply and passes through the high maximum at about $550^{\circ} \mathrm{C}$.

Concerning alloy $C$, the effect of pre-annealing on $Q^{-1}$ is more progressive and long-time thermal creatments are necessary to obtain a stabilization of the structure in regards of structural relaxation phenomena. For this alloy, interesting data are obtained from the spectrum in Fig.5 because a maximum emerges from the internal friction background at about $420^{\circ} \mathrm{C}$. Horeover after long-time pre-annealings (5-9 hours) the internal friction evolucion is restricted to two maxima, the first one at $420^{\circ} \mathrm{C}$ and the second one ac $540^{\circ} \mathrm{C}$. Whatever the alloy is, A or C,pre-annealing treatments lead to internal friction spectra where no evolution is detectable up to the Curie transition. Above this temperature internal friction increases as undefined premcryscallization phenomena occur and then crystallization stages take place.

\section{DISCUSSION}

In view of internal friction results of "as-cast" $A$ and B amorphous alloys, their $Q^{-1}$ evolution can be divided into four stages. The first one, from room temperature co $200-250^{\circ} \mathrm{C}$, must be concerned by liccle atomic rearrangements because of the light evolution of $\mathrm{Q}^{-1}$ in this temperature range. The second one,characterized by a low and large maximum at about $300^{\circ} \mathrm{C}$, was attributed to structural relaxation. However this phenomenon is thought to be partly hysteretic in view of the non-reversible character of this maximum when thermal cycles are performed between room temperature and $350^{\circ} \mathrm{C}$.A third stage between 400 and $500^{\circ} \mathrm{C}$ is more difficult to explain. In this temperature range the Curie transition and possibly some phenomena associated with the glassy transition occur,but the two little maxima observed in this stage are not explained (1).Finally the last stage, where two narrow and high maxima are detected, was related to crystallization phenomena. The first maximum corresponds to the alloy decomposition into $\mathrm{Fe}$ and $\mathrm{Fe}_{3} \mathrm{~B}$ compound, the second one is concerned by the transformation into Fe2B. This result was supported by electron microscopy (2)and differential bcanning calorimetry experiments ( 3 )as it will be shown in the following text for Fenimob alloys.

Precisely in the case of this last alloy the internal friction spectrum of "ascast" specimens exhibits two large maxima, at 250 and $350^{\circ} \mathrm{C}$ respectively, and a narrow one at $540^{\circ} \mathrm{C}$. The first maximum was connected with structural relaxation, the explanation of the second one would be difficult without the effect of annealing results. Indeed in these experiments a maximum emerges from the background level and this maximum corresponds to the crystallisation process according to thermal analysis data. Consequently the second large maximum observed in the "as-cast" conditions is assumed to be the superposition of ferromagnetic or glassy transitions phenomena on a first stage in the recrystallization progress. Finally the maximum detected at $540^{\circ} \mathrm{C}$ was attribuced to a second stage of the crystallization phenomenon. These results, concerning the partition of crystallization into two stages, was supported by scanning differential calorimetry experiments performed on alloy $C$ (Fig.6)

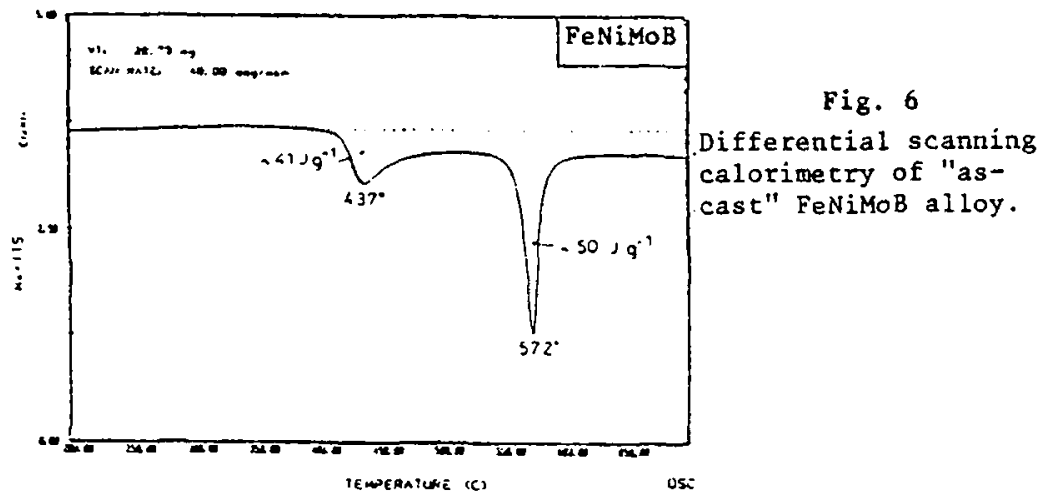


From the results on the effect of cold-working on internal friction spectra,the main feature is the enhancement of the maximum associated with the structural relaxation. If the relaxation part of this phenomenon is assumed to be characterized by a large spectrum of relaxation times (4), our explanation (5) is based on the possibility of a decrease of the total number of atomic configurations varieties under the effect of the temperature (relaxation times spectrum narrower) and a correlative increase of the number of atomic arrangements of a particular topology (higher contribution to internal friction level).

Informations on the possible effects of cold-working or pre-annealing treatments on the crystallization phenomenon were expected from internal friction spectra but the obtained results were not clearly explainable.Only cold-working seems to have little influence on the crystallization progress but more experiments have to be performed.

\section{CONCLUSION}

The ferromagnetic amorphous alloys which have been studied,exhibited important internal friction fluctuations related to atoms reorganization under the effect of the temperature. According to the nature of the rested material, the internal friction evolution as a function of the temperature is quite different, nevertheless in each alloy it appeared that $a$ wide and low maximum could be associated with structural relaxation while high and sharp maxima were related to two stages in the crystallization process.

Cold-working treatments increased the internal friction background and modified the shape of the maximum connected with the structural relaxation. This result was attributed to modification and redistribution of atomic aggregates configurations. cold-working treatments seemed to modify the crystallization process but the results are not reproducible.

Concerning the influence of pre-annealing on the internal friction behaviour of the studied alloys,it was shown the occurrence of a significant evolution in the temperature range where structural relaxation took place. When structural relaxation is completely achieved, on internal friction spectra anomalies are restricted to Curie transition and to erystallization stages.

Among the tested amorphous materials, FeNiMoB alloy exhibited a specific behaviour in that sense that important internal friction fluctuations, as a function of the temperature, revealed a high atomic mobility in the low temperature range.Such a phenomenon could be used for diffusion experiments between amorphous metallic films.

\section{REFERENCES}

I. N. Morito, T. Egami, Acta Met. 32, 603 (1984).

2. A. Quivy, Thèse - Université Paris VI (Déc. 1985), Paris.

3. J. Devaud-Rzepski, A. Quivy, M. Harmelin, J.P. Chevalier, Y. Calvayrac, First international workshop on non crystaliine solids (San Feliu de Guixols Mai 1986).

4. Z.z. Shi, 2.X. Wang, Proc. of the $8^{\text {th }}$ I.C.I.F.U.A.S. - Urbana 1985 (U.S.A.)

J. de Physique C 1046,469 (1985).

5. M. Aboki, G. Bouquet To be published in Scripta Met.

ACKNOWLEDGMENTS

The authors wish to thank Ms. M. Harmelin for valuable D.S.C. experiments. 